Published in final edited form as:

Annu Rev Sociol. 2015 August ; 41: 291-310. doi:10.1146/annurev-soc-073014-112326.

\title{
Incarceration and Health
}

\author{
Michael Massoglia ${ }^{1}$ and William Alex Pridemore $^{2}$ \\ ${ }^{1}$ Department of Sociology, University of Wisconsin-Madison, Madison, Wisconsin 53706 \\ ${ }^{2}$ Department of Criminal Justice \& Criminology, Georgia State University, Atlanta, Georgia 30302
}

\begin{abstract}
The expansion of the penal system has been one of the most dramatic trends in contemporary American society. A wealth of research has examined the impact of incarceration on a range of later life outcomes and has considered how the penal system has emerged as a mechanism of stratification and inequality in the United States. In this article, we review the literature from a comparatively new vein of this research: the impact of incarceration on health outcomes. We first consider the impact of incarceration on a range of individual outcomes, from chronic health conditions to mortality. We then consider outcomes beyond the individual, including the health of family members and community health outcomes. Next, we discuss mechanisms linking incarceration and health outcomes before closing with a consideration of limitations in the field and directions for future research.
\end{abstract}

\section{Keywords}

incarceration; health; mortality; inequality; stress

\section{INTRODUCTION}

This article reviews the sociological literature on the effects of incarceration on health, focusing specifically on physical morbidity and mortality. During the last four decades the American penal system grew at an unprecedented rate. The incarceration rate, which was roughly stable for 50 years prior to 1975, increased approximately fivefold since 1975 (Pettit $\&$ Western 2004). More than six million US residents are now or have been incarcerated and there are over 17 million felons or ex-felons in the United States. These numbers demonstrate the massive size of the penal system, and the current felon population is approximately six times larger than it was in 1970 (Uggen et al. 2006). Although the expansion of the penal system has affected all demographic groups, the impact was most acute for disadvantaged minorities and minority communities, for which rates of incarceration are five to eight times higher than rates for similarly situated whites (Pettit \& Western 2004).

\section{DISCLOSURE STATEMENT}

The authors are not aware of any affiliations, memberships, funding, or financial holdings that might be perceived as affecting the objectivity of this review. 
The penal system grew so large and so rapidly it now draws comparisons to the American system of higher education. Each year approximately as many men graduate college as are released from prison (Knapp et al. 2008), and the size of the incarcerated population (Glaze \& Parks 2012) is approximately the same as the enrollment at all American research universities (Snyder \& Dillow 2010). Given this rapid expansion and the wide swath the penal system cuts through American society, some argue incarceration is now a phase in the life course for some population subgroups (Pettit \& Western 2004) and that correctional policies have created a new felon class in American society (Uggen et al. 2006).

This remarkable growth produced a groundswell of research highlighting the far-reaching consequences of incarceration. For example, research illustrates the consequences of incarceration for family functioning, including the mental health of inmates' partners, the behavior of their children, and the impact of incarceration on marital dissolution (Comfort 2007, Goffman 2009, Lopoo \& Western 2005, Massoglia et al. 2011, Turney et al. 2012, Western \& Wildeman 2009). A related line of research reveals the stratifying impact of incarceration on economic indicators such as childhood poverty and on wages and entrance into the labor market (Pager 2003, Pager et al. 2009, Western 2002, Wildeman 2009). Scholars are becoming increasingly aware of the stratifying impact of incarceration and penal sanctions on a range of social and economic inequalities (Harris et al. 2010, Wakefield \& Uggen 2010). Given that the expansion of the penal system has disproportionately impacted minorities (Pettit \& Western 2004), it is important to consider whether and to what extent minorities and minority communities disproportionately feel the indirect consequences of the expansion. At least two distinct processes may drive any disproportionate impact of the penal system (Massoglia 2008b). First, as a percentage of the population many more minorities are exposed to the penal system, so even if the effect is the same across different races the aggregate impact will be larger for minority groups. Second, for a variety of reasons the detrimental consequences of incarceration could be felt more strongly by minorities. Thus, the current state of the field shows incarceration has emerged as a mechanism of stratification in American society and contributes to racial inequality.

Against this backdrop, the impact of incarceration on health outcomes and inequalities has received considerable attention, and in this article we review this body of research. We begin by discussing the general association between incarceration and individual health functioning. From there, we expand our scope and consider the impact of incarceration on family and neighborhood indicators of health. Next, we discuss the literature on the association between incarceration and mortality. Following that, we consider whether incarceration may have health benefits for some demographic groups. We then discuss the key potential sociological explanations for the relationship between incarceration and health. We conclude by discussing some of the limitations of the research on incarceration and health and then outline an agenda for future research in the incarceration-health tradition.

\section{INCARCERATION AND MORBIDITY}

\section{Individual Health}

A number of studies have examined the relationship between incarceration and a range of individual-level health outcomes. Some of the most innovative research in this area 
leveraged longitudinal data to examine within-person change in health status after a period of incarceration. Schnittker \& John (2007), for example, focused on within-person change using the National Longitudinal Survey of Youth (NLSY79). Three findings from this important paper set the stage for later sociological work in the area. First, the authors found that individuals with a history of incarceration report more chronic health problems after their period of incarceration than before. Second, the authors accounted for chronic health problems prior to prison, which allowed them to demonstrate empirically that incarceration is associated with a negative change in health status. Third, Schnittker \& John found that the impact of the length of incarceration on health appears to be less important than the fact of incarceration itself.

Other works utilizing the same data set (NLSY) reached similar conclusions. For example, Massoglia (2008a) found that incarceration is correlated with lower self-reported health and that having been incarcerated was more consequential than the length of incarceration. Similarly, using the same data set, Massoglia (2008b) found that relative to those who had not been incarcerated, those who had been incarcerated disproportionately suffer from infectious diseases (e.g., hepatitis, tuberculosis) and stress-related illness.

Other studies looked at different aspects of health and considered the potential impact of incarceration. For example, obesity is a socially patterned epidemic with higher prevalence among those of lower socioeconomic status and among ethnic/racial minorities. For instance, Houle (2014) investigated how incarceration might contribute to patterns of obesity. The author examined trajectories of body mass index (BMI) and found that being incarcerated increases BMI. The effects varied, however, with strongest effects for blacks and for individuals with less education. In the conclusion the author echoed a common theme across many studies in the area: Given the disproportionate rates of incarceration, and the stronger effects for blacks, the penal system may condition the structure of obesity disparities across the life course (Houle 2014). ${ }^{1}$

\section{FAMILY, NEIGHBORHOOD, AND POPULATION HEALTH}

An emerging literature examines the detrimental impact of incarceration on family, neighborhood, and population health. The impact of incarceration on health, including mental health (Wildeman et al. 2012), extends to family members (including partners and children) of those who are incarcerated (Wakefield \& Wildeman 2013, Wildeman \& Muller 2012). Roettger \& Boardman (2012) used the National Longitudinal Study of Adolescent Health to investigate the impact of parental incarceration on childhood body mass. Using multiple analytic approaches and accounting for several potentially confounding factors such as stressful life events and individual and family characteristics, the authors found that parental incarceration is associated with increased body mass among female, but not male, children of those who were incarcerated.

\footnotetext{
${ }^{1}$ Although our review focuses on the sociological literature, the medical field also has begun to investigate the association between incarceration and health problems. One example used the Coronary Artery Risk Development in Young Adults (CARDIA) and found increased prevalence of hypertension and left ventricular hypertrophy among individuals with a history of incarceration (Wang et al. 2009).
} 
Lee et al. (2014) also found that results vary by gender. Having a family member incarcerated increased the likelihood of women to experience a heart attack, stroke, or obesity or to have fair to poor health. There was no relationship found among males who had a family member incarcerated. This study revealed that the incarceration of a family member has implications for women's cardiovascular health and, consistent with other literature in the area, that incarceration contributes to overall racial disparities in health. Given the current data limitations of studying incarceration and health, this study is also notable because it utilized the National Survey of American Life, a cross-sectional, nationally representative study.

The Fragile Families and Child Wellbeing Study is one of the most widely used data sets to study the effects of incarceration on families (see Wildeman \& Western 2010). What becomes clear from fragile families, and is relevant for understanding the health problems associated with incarceration, is that the families most likely to be affected by incarceration are often disadvantaged socially, residentially, and economically. That is, the families most likely to experience incarceration are already at risk for problematic outcomes, including poor health.

In contrast to other research that focuses on the direct effects of incarceration on health outcomes, many of the harmful effects of incarceration on children's health operate indirectly through other mechanisms, including family processes (Arditti et al. 2003, Waller \& Swisher 2006), relationships among partners (Comfort 2008), changes in economic wellbeing (Geller et al. 2011, Schwartz-Soicher et al. 2011), or educational performance (Cho 2009a,b). In short, paternal incarceration affects child health through its detrimental impact on family and attainment processes important to children's health, such as educational, labor market, and residential attainment.

In a comprehensive treatment of the topic, Wakefield \& Wildeman (2013) concluded incarceration has wide-ranging effects on childhood health and well-being, including increasing mental health and behavioral problems. Because the risk of paternal incarceration is much higher for black children than for white children, Wakefield \& Wildeman (2011, 2013) concluded that parental incarceration is an important contributor to racial disparities in childhood health and well-being.

Parental incarceration also leads to poor health outcomes by increasing the likelihood that children will adopt behaviors associated with poor health. For instance, parental incarceration is associated with behavioral problems in children (Geller et al. 2011; Murray et al. 2012a,b), including physical aggression (Wildeman 2010) and criminality (Roettger \& Swisher 2011). Parental incarceration also leads to increased drug and alcohol use among children, which has obvious implications for the health of children (Roettger et al. 2011). Research also suggests maternal incarceration may have stronger negative effects on children than paternal incarceration does (Murray \& Farrington 2008).

Turney (2014) provides an insightful and timely bridge between family health outcomes and larger community and population health outcomes. Even after accounting for an array of relevant factors, Turney found an independent impact of incarceration on outcomes ranging 
from behavior and conduct problems to developmental delays. She concluded that children's health disadvantages are an overlooked consequence of incarceration, arguing that proliferation of stress across generations is a mechanism by which parental incarceration influences the health of children. Perhaps more importantly, Turney suggested that given its unequal distribution across different demographic groups in the population, incarceration may have implications for population-level class and ethnic inequalities in children's health.

Turney's findings are consistent with research that documents many detrimental effects of incarceration on community and public health (see discussion in Massoglia \& Schnittker 2009). One such study used state-level panel data stretching almost 25 years and found an association between incarceration and poorer population health. This association is strongest for infant mortality and female life expectancy (Wildeman 2012). Another study examined the relationship between incarceration and infection rates of immunodeficiency syndromes ( Johnson \& Raphael 2009). The authors found that incarceration had a significant effect on AIDS infection rates for both males and females and concluded that a large proportion of the racial disparities in AIDS infections among black women can be explained by higher incarceration rates among black men ( Johnson \& Raphael 2009). One compelling aspect of this study is its use of data from the Centers for Disease Control and Prevention and caselevel US data spanning the period 1982-1996, making it both longitudinal and representative.

\section{INCARCERATION AND MORTALITY}

\section{Mortality During Incarceration}

Studies examining mortality within the prison and comparing within-prison mortality with that of the general population are rare. Mumola (2007) used national-level data to summarize within-prison mortality and compare it with the rates for the US resident population. Although his comparisons between the two populations were not adjusted for differences in age and sex, the results are telling. There were approximately 3,000 deaths per year in US prisons between 2001 and 2004, corresponding to an average annual mortality rate of 250 per 100,000 prisoners. Eighty-nine percent of prison deaths were due to internal causes, with suicide ( $6 \%$ of all deaths) the only external cause in the 10 leading causes of death among prisoners. Other external causes such as homicide, alcohol/drug overdose, and accidental injury comprised $2 \%, 1 \%$, and $1 \%$ of deaths, respectively. The leading causes of death were heart disease (annual rate of 68 per 100,000 prisoners) and cancer (58 per 100,000), followed by liver diseases ( 25 per 100,000), AIDS (18 per 100,000), and suicide (15 per 100,000). Approximately two-thirds of all deaths, including over $90 \%$ of all AIDSrelated deaths, resulted from conditions that existed when the inmate entered prison. There was substantial state-level variation in the mortality rate due to internal causes among those incarcerated: the rate in Louisiana, Tennessee, Pennsylvania, West Virginia, and Kentucky was approximately three times higher than the rate in Utah, North Dakota, Iowa, Alaska, and Vermont.

In a study of mortality among Texas male inmates between 1992 and 2003, Harzke et al. (2011) found the leading causes of death to be infections, cancer, and cardiovascular disease. Sixty-nine percent of deaths due to infection were caused by AIDS, though as shown in 
other analyses the inmate death rate due to infection declined substantially over time. Nevertheless, after adjusting for age and race, the authors found that annual mortality rates due to infection were still two to three times higher in the incarcerated population than in the general population of Texas. Inmate deaths due to cardiovascular diseases also dropped sharply over this period, as did deaths due to cancer and liver disease, leading the authors to conclude that changes in health care in the Texas prison system over time-including improvements in screening protocols, in infirmary and outpatient capacity, and in specialty care-may have been responsible for the declines.

Using data from the Bureau of Justice Statistics and the Census Bureau for the period 19851998, Patterson (2010) compared sex- and ethnic-specific mortality rates for prisoners and non-prisoners aged 18-65. Although most studies focus on men, Patterson found incarceration to have stronger effects on female mortality than on male mortality. Her results also showed white male prisoners experienced significantly higher death rates than white male nonprisoners did. Using data on men aged 20-79 in North Carolina for the period 1995-2005, Rosen et al. (2011) compared mortality rates of prisoners with those of nonprisoners. The all-cause standardized mortality ratio (SMR) for white inmates was 1.12, with more deaths than expected from HIV and viral hepatitis infections, liver disease, cancer, and respiratory disease. In a retrospective cohort study, Spaulding et al. (2011) examined all persons in Georgia prisons on June 30, 1991, to determine their survivability through the end of 2006. As with prior studies, the authors found white men were at a substantially higher risk for mortality (SMR $=1.28)$ while incarcerated than when not incarcerated. The results of these studies suggest white men are at an increased risk of mortality when living in prison than when not living in prison, and that this risk is driven largely by deaths due to infectious diseases, cardiovascular disease, and cancer. The findings, however, are different for black men.

\section{Does Incarceration Reduce Mortality Among Black Men?}

In spite of the growing body of research demonstrating the negative health implications of incarceration, there is increasing evidence that incarceration has a protective effect on mortality rates for black men. Using national-level data, Mumola (2007) found that the mortality rate for black male prisoners aged 15-64 was 19\% lower than that for black men in the general population. This was driven, however, by differences in ethnic-specific mortality rates. Incarcerated whites and Hispanics had mortality rates slightly above those for the corresponding groups in the general population, whereas the mortality rate for incarcerated blacks was 57\% lower than the rate for blacks in the general population. Patterson's (2010) results also revealed that the substantial inequality in mortality rates for blacks and whites in the general population largely disappeared in the incarcerated population. She found that whereas the within-prison mortality rate for white males was higher than the rate for white males in the general population, the within-prison mortality rate for black males was considerably lower than the rate for black males in the general population. Similarly, using standardized mortality ratios to compare death rates of males in North Carolina prisons with expected death rates based on state residents, Rosen et al. (2011) found 48\% fewer deaths than expected among black prisoners. 
Why might incarceration protect black males against mortality? First, the controlled prison environment can protect against external causes of death, such as violence and transport accidents, that are high among young black males in the general population (Patterson 2010, Rosen et al. 2011), especially because those incarcerated are probably among the most at risk of death from these causes. Second, low-income black males of all ages may benefit from the availability of healthcare in prison, which would be largely either inaccessible or unused outside prison. Patterson (2010), for example, found that the differential mortality rate between incarcerated and nonincarcerated young black men was not entirely accounted for when firearm and motor vehicle deaths were removed from the general population comparison group. Further, Rosen et al. (2011) found that not only traumatic but also chronic causes of deaths such as cardiovascular disease and cancer were lower than expected among incarcerated black males. Chronic causes of death are more common to an older population. Thus, the food, shelter, and especially medical care provided in prison may protect black males against mortality. The hypothesis of better health care for blacks inside prison relative to outside prison received further evidence from another study by Rosen et al. (2008), who found fewer than expected all-cause deaths and deaths from chronic disorders among black former inmates. The authors of these studies concluded that different aspects of the prison environment, both environmental controls and provision of services, equalize the ethnic mortality disparities outside prison.

Another study, however, suggests an alternative explanation. The practice of compassionate release, i.e., releasing inmates who are in particularly poor health and close to death, is not uncommon in some states. Compassionate release reduces the mortality rate of the incarcerated population and increases the mortality rate of the comparable resident population. In their study of mortality among current and former Georgia prisoners, Spaulding et al. (2011) initially found a substantially lower mortality rate among incarcerated black men relative to nonincarcerated black men. After controlling for the compassionate release of moribund prisoners, however, the effect disappeared. Thus, although environmental controls of the prison may protect against external causes of death for young black men, findings indicating that health care is better for incarcerated black men may stem from an artifact of end-of-life prison policies, and more research is required before definitive conclusions can be drawn.

\section{MORTALITY IMMEDIATELY FOLLOWING RELEASE FROM PRISON}

The majority of studies of incarceration and postrelease mortality examined short-term effects. Analyses conducted in several nations consistently revealed the period immediately following release from prison to be extremely dangerous for ex-inmates (Bird \& Hutchinson 2003; Farrell \& Marsden 2008; Graham 2003; Kariminia et al. 2007a,b; Pratt et al. 2006; Seaman et al. 1998). Binswanger et al. (2007) undertook a retrospective cohort study of all inmates released from the Washington State Department of Corrections between 1999 and 2003, and compared their mortality rates with those in the state population. Adjusting for age, sex, and ethnicity, the mortality rate for recently released inmates during the entire follow-up period was 777 per 100,000 person-years, which was 3.5 times higher than the rate for the general population. In the first two weeks following release, the death rate was nearly 2,600 per 100,000 person-years, or approximately 13 times higher than the rate for 
the general population. The authors' finding of a considerable mortality risk in the first two weeks following release from custody is consistent with results from other studies of both prisons (Bird \& Hutchinson 2003, Kariminia et al. 2007b, Krinsky et al. 2009, Seaman et al. 1998, Verger et al. 2003) and jails (Lim et al. 2012).

By a wide margin, the leading cause of death for ex-inmates during the immediate postrelease period is drug overdose. Additional leading causes of death during this time include external causes such as homicide and suicide. During this period deaths due to drug overdose are likely the result of several factors related to (a) the behavior of the individual, including polydrug use (especially involving opioids) and decreased physiological tolerance during a period of little or no use while incarcerated, and $(b)$ the interaction between the individual and the criminal justice system, including the failure to properly identify those most at risk, improper or absent prerelease planning and counseling, and little or no provision of health care or follow-up after release (Møller et al. 2010). Further studies are required to determine which characteristics put ex-inmates most at risk of death, not only from drug overdose (Binswanger et al. 2011, Møller et al. 2010) but also from other preventable causes such as homicide and suicide (Pratt et al. 2006), during this period.

\section{LONG-TERM EFFECTS OF INCARCERATION ON MORTALITY}

Although fewer studies examined the long-term impact of incarceration on mortality, this is an important exercise because it allows scholars to determine whether any effects of incarceration on morbidity translate to early mortality, whether incarceration increases the risk of premature mortality from internal and chronic causes of death relative to the external and acute causes of death, and whether ex-inmates are at a higher risk of death immediately following release. The results from studies showing the long-term effects of incarceration on mortality are less consistent than those showing short-term effects.

Some studies found an association between incarceration and mortality. In an analysis that linked prison and state death records in North Carolina over a 25-year period, Rosen et al. (2008) used SMRs to compare the mortality of male ex-inmates aged 20-69 with that of other state residents. Although all-cause mortality was higher among ex-prisoners than among other state residents, there were large differences by ethnicity. The all-cause SMRs were 2.08 for whites and 1.03 for blacks (though the latter effect was small, it was statistically significant). The authors found that former inmates had higher-than-expected mortality from homicides, accidents, substance use, HIV, liver disease, and liver cancer. Spaulding et al. (2011) linked prison and death records and estimated SMRs to examine mortality among the cohort of all persons incarcerated in Georgia state prisons on June 30, 1991, through 2006. They found positive and significant SMRs for all ex-inmates and for sex- and ethnic-specific ex-inmate groups. Again, however, SMRs were larger for whites (2.12) than for blacks (1.32). The authors included women in their study and found that SMRs were larger for women (2.56) than for men (1.51). The authors' results revealed that HIV, cancer, cirrhosis, homicide, transport accidents, and overdoses accounted for nearly two-thirds of the excess mortality among former prisoners. 
Utilizing data from a large-scale population-based case-control study of Russian men aged 25-54 and controlling for the known causes of premature mortality among this group, Pridemore (2014) estimated mortality odds ratios to examine the association between incarceration and premature mortality. He found that, relative to men who had not been incarcerated, men who had been incarcerated were more than twice as likely to die prematurely. Comparing the age-adjusted odds of specific causes of death of decedent men who had been incarcerated with those of decedent men who had not been incarcerated, the author found the former were more likely to die from infectious diseases $(O R=3.10)$, drug overdose $(O R=2.32)$, homicide $(O R=1.99)$, and respiratory disease $(O R=1.79)$. Patterson (2013) used data from New York state to study the impact of incarceration length on postprison mortality. Her results showed that each additional year in prison produced a nearly $16 \%$ increase in the odds of death and a two-year decline in life expectancy. Thus, for someone 30 years old five years in prison would increase the odds of death by approximately $80 \%$ and result in a loss in life expectancy of approximately 10 years. As with other studies she found the risk of mortality was highest immediately following release from prison, with the time to recovery equal to approximately two-thirds of the time served in prison. Patterson concluded that incarceration length has a direct impact on life expectancy.

Other evidence suggests incarceration has no long-term effect on mortality. First, although the studies described above have longer-term follow-up periods, they include deaths from the time immediately following release from prison. These deaths may be driving any association found between incarceration and premature mortality, especially because we know many of the excess deaths in these studies of long-term effects resulted from the same causes of death common in studies of mortality during the immediate postrelease period, including drug overdose, homicide, and suicide. Similarly, although Patterson (2013) found that the length of incarceration has dramatic effects on the odds of death and on life expectancy, she also found (a) that return to baseline odds of death occurred after approximately two-thirds of the individual's incarceration length and (b) that $70 \%$ of the individuals in her sample were incarcerated less than two years and $86 \%$ less than three years.

Second, some studies reveal no association between incarceration and premature mortality. For example, Kjelsberg \& Laake (2010) examined all-cause and cause-specific mortality among Norwegian male and female convicted offenders, some of whom had experienced incarceration and some of whom had not. Whereas the unadjusted odds ratio for incarceration was significantly associated with all-cause mortality for men, it was nonsignificant when adjusted for the other variables in the model. Further, they found no association between incarceration and all-cause mortality for women, nor were there effects of incarceration on deaths from substance abuse, accidents, homicides, or suicides. In a study of incarceration and premature mortality using the National Longitudinal Survey of Youth (NLSY79), Massoglia et al. (2014) found differential effects by gender. In their sample, women who had been incarcerated were approximately 2.5 times more likely to die prematurely than women who had not been incarcerated. However, incarceration had no effect on premature mortality for men. This stronger effect for women is consistent with the findings from Spaulding et al. (2011). 
Finally, Dirkzwager et al. (2012) studied the effects of first-time incarceration on postprison mortality over a 25-year period among a representative group of over 2,000 Dutch offenders who were convicted in 1977. Their findings were equivocal. Results showed that those who had been incarcerated were significantly more likely to die during the follow-up period when compared with the general population $(O R=3.21)$ and with a group of convicted offenders who had not been incarcerated $(O R=1.47)$. After applying propensity score analysis, however, the matched formerly incarcerated group was not at a significantly greater risk of death than the matched control group $(O R=1.40 ; 95 \%$ confidence interval: 0.95-2.07). Thus, only a handful of studies have examined incarceration and premature mortality with a long-term follow-up, and the inconsistent findings suggest further research is required before strong conclusions can be drawn.

\section{PATHWAYS LINKING INCARCERATION TO NEGATIVE EFFECTS ON HEALTH}

Space limitations preclude us from discussing all possible pathways that explain why incarceration may have negative effects on health. Therefore, we focus our discussion on the potential explanations that have received the most attention in the sociological literature.

\section{Exposure to Infectious Diseases}

Although many inmates with an infectious disease entered correctional facilities with the infection, the prison places inmates at a disproportionate risk of acquiring infectious diseases such as tuberculosis, hepatitis, HIV, sexually transmitted infections, and methicillin-resistant Staphylococcus aureus (Maruschak 2008). Approximately 25\% of US inmates have latent tuberculosis infection, which is 6 to 10 times higher compared with the general population (Bick 2007). Approximately $17 \%$ of inmates have hepatitis C compared with approximately $2 \%$ of the general population, with the prison population housing nearly $30 \%$ of all hepatitis $\mathrm{C}$ cases in the United States (Varan et al. 2014). Compared with approximately $0.3 \%$ of the general population, approximately $1.5 \%$ of inmates are HIV positive (Maruschak 2012). As in the general population, cases of hepatitis $\mathrm{C}$ and HIV in the incarcerated population declined considerably between 2000 and 2010 . The disproportionate exposure to infectious diseases for inmates occurs in the context of a prison environment with efficient conditions for disease transmission: overcrowding; poor ventilation; poor nutrition; shared hygiene facilities; shared personal hygiene items such as soap and razors; poor health care; delayed diagnosis; lack of expertise in infection control; prohibitions against effective harm reduction techniques such as use of condoms; and practices such as amateur tattooing and piercing, unprotected sex, and use of unsterilized drug injection equipment. Contracting a disease while in prison increases the chances of ill health upon release and, in the case of tuberculosis, hepatitis $\mathrm{C}$, and HIV, increases the risk of premature mortality.

\section{Incarceration as an Acute and Chronic Stressor}

Incarceration is an acute stressor. Imprisonment is a major life event that requires dramatic changes in a short period across a number of life circumstances (Massoglia 2008a).

Research shows such events cause considerable stress, which can have negative repercussions for health (Thoits 1995, Wheaton 1994). Incarceration is also a chronic 
stressor (Pearlin 1989). Imprisonment can last for years, adding chronic stress to the initial acute shock. Daily stressors in prison can include lack of privacy, overcrowded conditions, antagonistic relationships with guards and inmates, witnessing violence, and the threat of violent victimization. Upon release from prison, former inmates must deal with enduring stressors such as social stigma and the disruption of social bonds such as employment and relationships with family and friends.

Research consistently shows that stress is negatively associated with health. Exposure to repeated or chronic stressors increases allostatic load, which can lead to negative health outcomes (McEwen \& Stellar 1993). The psychoneuroimmunology literature, for example, reveals that chronic stress is associated with immune dysfunction (Glaser \& Kiecolt-Glaser 2005), and research shows that chronic exposure to hostile conditions-a staple of prison life-is associated with immune dysfunction that can last for long periods. According to Pridemore (2014, p. 217), this "stress-induced immune dysfunction perversely increases the inmate's vulnerability at precisely the time when exposure to infectious diseases is greatest, during imprisonment." Beyond the confines of the prison, Schnittker \& John (2007) found evidence suggesting the enduring social stigma of imprisonment mediates the association between incarceration and health, and Massoglia (2008a) found that former prisoners had increased risks of (a) being medically diagnosed with stress-related illnesses such as psychological problems, hypertension, and heart disease, and (b) self-reporting stress-related conditions such as chest pain and depression.

\section{Incarceration as an Impediment to Social Integration}

Incarceration is extremely disruptive to social integration and prosocial bonds. First, imprisonment makes it difficult to maintain stable family and friendship networks. The stigma attached to those who have been incarcerated makes them less desirable partners (Wilson 1987) and they have lower marriage rates following imprisonment (Huebner 2005). Individuals married at the time of incarceration have a greater risk of divorce both during and after imprisonment (Apel et al. 2010, Massoglia et al. 2011). Siennick et al. (2014) found that such marriages are at increased risk of poor marital quality, relationship violence, and extramarital sex and that these factors explain approximately $40 \%$ of the association between incarceration and divorce. Second, in many instances daily prison life requires social and psychological adaptations that make it difficult to reintegrate into the community and to develop and maintain healthy friendships following release (Braman 2004).

Third, the effects of incarceration on employment and earnings are varied but substantial. Experimental evidence shows that employers are biased against hiring former inmates (Pager 2003), and in their sample of Dutch offenders Ramakers et al. (2014) found a doseresponse relationship between length of incarceration and poor employment prospects. Exinmates have limited access to career-oriented occupations and thus are often relegated to undesirable jobs with low wages, poor benefits, and no health insurance. Incarceration is associated with lower earnings growth over one's employment career (Sampson \& Laub 1993) and with a wage penalty of 10-30\% (Western et al. 2001). Western (2002) found the impact of incarceration on wage mobility so strong and the prevalence of imprisonment among black men so high, he concluded that incarceration is partially responsible for 
aggregate-level ethnic wage inequality in the United States. In short, incarceration is a major turning point in the life course and is remarkably disruptive for social integration (Sampson \& Laub 2003).

Social integration and prosocial bonds, including education, marriage, social support, employment, and income, provide protective effects against morbidity and mortality. Marriage has long been associated with better health and increased longevity, especially for men (Verbrugge 1979). Using the same data from a case-control study of Russian men that showed an association between incarceration and premature mortality (Pridemore 2014), Pridemore et al. (2010) found that marriage and education were inversely associated with the risk of premature mortality. Declines in perceived health and physical functioning are slowed by full-time employment (Ross \& Mirowsky 1995) and income is inversely associated with both morbidity and mortality (Backlund et al. 1996, Ecob \& Davey Smith 1999). Given these findings, Pridemore (2014) argued that social integration and prosocial bonds likely play key mediating roles in the relationship between incarceration and premature mortality.

\section{LIMITATIONS OF RESEARCH ON INCARCERATION AND HEALTH}

\section{Data}

There are several limitations to prior research on incarceration and health. One of the most pressing issues in this area is data scarcity. A few data sets, for instance, the Fragile Families and Child Wellbeing Study, the National Longitudinal Survey of Youth 1979 and 1997, and the National Longitudinal Study of Adolescent Health, have been the source of data for a great deal of research in the area. Each data set has different strengths and weaknesses and scholars have been successful in moving the field forward using each, but a common thread permeates them: All are secondary data designed to study other phenomena and social processes. Given this, it becomes challenging to adequately address important issues such as selection effects (see below).

Data limitations in this area also impact the most basic aspects of research: the dependent and independent variables. Data on incarceration are comparatively scarce and there is considerable variation in how incarceration is operationalized. Some studies operationalize incarceration as a short period in a jail, others as imprisonment of over a year, and others as lifetime prevalence of incarceration. Although each of these measures has potential strengths and weaknesses, it is necessary to move research toward greater conceptual clarity on the treatment variable and to consider how different operationalizations of incarceration might condition findings. Similar problems can often plague the outcome variables. Studies thus far commonly employ different operationalizations of health, making it difficult to compare results. Finally, perhaps most pressing is the need for longitudinal measures of health outcomes. We know inmates have more health problems than noninmates do, but moving toward causal claims places greater demands on the data, including repeated measures over time that allow scholars to employ a full range of analytical approaches. 


\section{Proper Comparison Groups}

We know that inmates have increased medical problems compared with the general population (Binswanger et al. 2009), but absent more information it remains unclear whether differences are a function of incarceration or of characteristics that are related both to health and to the likelihood of incarceration. Thus, with whom we compare (ex-)inmates is of paramount importance. Much work, including some of ours, compares inmates with noninmates after adjusting for a number of covariates. Although data limitations often prevent more fine-grained comparative analysis, the problems of covariate adjustment for causal inferences are well known. Although within-person change models, often termed fixed-effects or individual trajectory models, offer the most stringent tests of the incarceration-health relationship, such analyses demand longitudinal data with repeated measures that are often lacking in this area of research. In cases in which data limitations prevent such analysis, a fruitful comparison group might be individuals convicted of a crime but not incarcerated. Compared with the general population, this group of convicted but nonincarcerated felons is more similar to the incarcerated population and thus might be a more appropriate comparison group. Regardless of the specific focus, as research in the area moves forward, increased attention to the appropriate comparison groups is required.

\section{Selection Effects}

One of the most pressing issues facing the research on incarceration and heath is potential bias from selection effects. As Johnson \& Easterling argued (2012, p. 342),

Despite what appears to be converging evidence that parental incarceration poses a significant threat to child development, this area of inquiry has yet to overcome important methodological and conceptual challenges related to selection bias. It is therefore unclear whether the difficulties that have been observed among children whose parents are incarcerated are due to the incarceration itself or to other adversities that children have experienced.

Although others have offered a thoughtful and systematic response to such critiques (Wildeman et al. 2013), our point is a basic one: Given how closely the correlates of incarceration map over the determinants of poor heath, scholars must pay particular attention to potential bias from selection effects and employ rigorous analytical methods and careful research designs to address it. Absent such careful consideration, this area of research remains open to critiques of selection bias. For instance, inmates may have poorer health profiles because of a history of drug use rather than incarceration itself. Along similar lines, perhaps the appearance of an effect of parental incarceration on children's health is actually a product of parental absenteeism, or maybe the apparent effect of incarceration on individual health is a product of earnings inequality or of individual or family characteristics early in life that increase the chances both of incarceration and of poor health. Although some research in the area has begun to address these important critiques, future research meant to estimate the precise magnitude of the impact of incarceration on individual, family, and community health must recognize the potential bias of selection effects. 


\section{AN AGENDA FOR FUTURE RESEARCH ON THE ASSOCIATION BETWEEN INCARCERATION AND HEALTH}

Although research on incarceration and health has rapidly grown in recent years, many important substantive and methodological items remain to be addressed. Although our suggestions are not exhaustive, we propose several important considerations for the scientific record as researchers move forward in understanding this relationship. One area that appears ripe for additional inquiry is the treatment variable. The literature takes a fairly broad view of the term incarceration. Without giving preference to one over the other, some data sets appear to capture more invasive spells of imprisonment, whereas others might capture just a few days in jail (e.g., see collection protocol differences between the National Longitudinal Survey of Youth 1979 and the National Longitudinal Survey of Youth 1997). According to recent data, the average sentence in state prisons is slightly over 4 years, with offenders serving roughly half of the sentence. In contrast, most spells in jail are less than 3 days, and many people who spend a few nights in jail are ultimately not convicted of any crime. Given these diverse treatments, future work should investigate whether these different types and lengths of correctional confinement produce divergent effects (Massoglia \& Warner 2011).

A related line of inquiry might examine how different levels of confinement-for example, minimum versus maximum security — might be associated with differences in and severity of adverse health outcomes. In addition, work has not considered whether there is state or regional variation in the incarceration-health relationship. It may be, for instance, that states with more integrative postrelease policies have better health outcomes. Along similar lines, although the United States is the world leader in terms of incarceration, comparative sociologically oriented work on incarceration and health is relatively sparse (Pridemore 2014). The field would surely be advanced if scholars brought more comparative approaches to this area. For example, incarceration may still affect health even in nations with lower incarceration rates and shorter sentence lengths. Yet research could examine, for instance, whether cultural differences across nations likely influence the structure of prisons and the experience of incarceration, both of which could affect any impact of incarceration on health (and of course on other collateral consequences of incarceration).

Research should also move toward a focus on the causal mechanisms linking incarceration to poor health outcomes. Thus far, research has done a better job showing that incarceration matters rather than why incarceration matters. A great deal of research discusses stress and stigma. Both potential mechanisms have pragmatic appeal and research in both criminology and medical sociology suggests they are appropriate explanatory mechanisms. To date, however, precise specifications of the causal pathways linking these and related factors to health have been elusive. Such causal pathways to poor health outcomes are notoriously difficult to model, but as this research area matures, identifying causal mechanisms must progress.

Greater research on female (ex-)inmates would also advance the field. To date, much of the work in the area has excluded female offenders. This omission is notable for a number of reasons. First, although much smaller, the size of the female incarcerated population is 
growing far faster than the size of the male population. Second, female inmates have a different set of risk factors across a number of areas-drug use, relationship history, history of abuse - that are likely linked to health outcomes (see Lindquist \& Lindquist 1997). Third, compared with men, women have a different set of health needs, suggesting that the incarceration experience may differentially impact women's health. The research of Massoglia et al. (2014) and Spaulding et al. (2011) provides evidence not only that the health consequences of incarceration are different for men and women but that the negative effects may be stronger for women, at least on some outcomes. Given the differences between male and female offenders, a sustained and focused inquiry into potential gender differences in the incarceration-health relationship seems particularly timely.

As research on the incarceration-health relationship moves forward, two other related substantive avenues for future research are important. At first view each avenue appears somewhat counterintuitive. This research area would be well served if future research considered the potential positive impact of incarceration on health at both the individual and community levels. Although research has clearly demonstrated a negative impact of incarceration on individual health across a variety of outcomes, other work has demonstrated differential effects of incarceration on family life (Wildeman \& Turney 2014), and a consideration of the potentially positive impact of incarceration on health is warranted for a number of reasons.

At the individual level, on average persons who are incarcerated often are drawn disproportionately from a disadvantaged background. Given less access to health care and the generally poorer health status of those from these disadvantaged backgrounds, the correctional institution may provide inmates with opportunities to improve their health. The correctional setting provides some inmates better access to fundamental health needs such as nutrition and a place to sleep that is heated and dry. Aside from these most basic health requirements, which surely are not met for some of these individuals outside of prison, the institution removes some individuals from destructive social environments that may include high levels of drug use and, particularly for women, a history of physical abuse. Removing individuals from such environments might provide some health benefits. Finally, although often lacking in several respects, health care provisions in prisons may represent a dramatic improvement over the care (if any) some inmates receive outside prison. In short, due to the extremely disadvantaged background from which many inmates are drawn, there is a rationale for exploring the possibility of a positive, even if short-term or limited, impact of incarceration on the individual health of some inmates. Our review reveals evidence of such potential short- and long-term positive effects of incarceration on health (Mumola 2007; Patterson 2010; Rosen et al. 2011, 2008). This is a sensitive topic, and obviously the policy response is not to increase incarceration in hopes of better health outcomes. The results are intriguing, however, and if they hold up, they will serve as a stark indicator of the generally poor health care provided to this segment of the population. Further, they would suggest the importance of better education about and more careful planning for postrelease health care and for more rational policies for sharing medical data with parole officers, social workers, and others tasked with aiding prisoners upon release. 
Similarly, the prison may produce other types of health benefits, in particular for treatable diseases. Again the potential benefits stem from the reality of the marginal or nonexistent health care inmates have on the outside, and at the aggregate level it is important to consider the remarkable expansion and size of the penal system. Correctional facilities offer an opportunity to impact the health profile of a large and underserved aspect of the community. Many state prison systems screen for and treat communicable diseases. For specific diseases or infections for which treatment can cure an illness or provide lasting improvement in health functioning, correctional facilities offer the potential to improve individual health and aggregate health inequities. For instance, because data indicate that a large number of individuals with treatable sexually transmitted infections are passing through correctional facilities, screening and treatment in prisons could not only improve individual health but also reduce the prevalence of infections in the general community. In short, given the high levels of inequality and health disparities characteristic of American society at both the individual and community levels, it could be fruitful to investigate how the penal system could produce some improvements in health outcomes.

A paramount item to address in future research is data collection and research design. To this point nearly all studies of the incarceration-health association employed secondary data.

This approach presents important methodological and theoretical challenges.

Methodologically, for example, many of these studies are vulnerable to selection bias. Theoretically, these data sets do not allow us to test several important hypotheses about the incarceration-health association because data collection was undertaken to answer other questions. Now that there is strong evidence that incarceration has consequences for individual, family, and community health, it is time to undertake large-scale projects that focus specifically on this association. These projects would involve original data collection aimed at and research designs capable of answering the most poignant theoretical questions now being posed in this research area. This type of original data collection would allow us to (a) address methodological limitations such as selection effects, (b) determine whether the health effects of incarceration are causal or spurious, and $(c)$ undertake tests of theory capable of discovering the direct, indirect, and conditional causal pathways through which incarceration influences health.

Finally, our review is notable for what fell outside our specific scope of inquiry. For example, space limitations prevented us from systematically reviewing the rapidly expanding literature on the impact of incarceration on mental health outcomes. ${ }^{2}$ Similar to the literature on physical health, the literature on the mental health consequences of

\footnotetext{
${ }^{2}$ We refrain from introducing a large discussion of the association between incarceration and mental health for two reasons. First, although this association is important, and historically and currently receives greater attention than the association between incarceration and physical health, our focus is squarely on the latter and we do not wish to distract from that discussion. Second, the association between incarceration and mental health examines a broad array of substantive topics and faces its own set of methodological challenges, and a brief introduction to this constellation of issues would not do them justice. Substantively, relative to the general population, prisoners worldwide have a greater prevalence of serious mental disorders (Fazel \& Danesh 2002). More than half of all jail and prison inmates in the United States have at least one mental health problem, and inmates with such problems are more likely to have experienced substance dependence, homelessness (Greenberg \& Rosenheck 2008), and physical or sexual abuse ( James \& Glaze 2006). Relative to male inmates, female inmates suffer higher rates of mental health problems and mental distress ( James \& Glaze 2006, Lindquist \& Lindquist 1997). Relative to other inmates, mentally ill inmates are more likely to have committed a violent offense and more likely to report at least three prior prison sentences (Ditton 1999). The use of solitary and supermax confinement has increased in the United States, and there are reasons to believe these conditions cause or exacerbate mental health problems (Haney 2003), as do other environmental conditions in prison such as negative relationships and staff shortages (Nurse et al.
} 
incarceration considers the impact on both inmates (Schnittker et al. 2012) and family members of those who are incarcerated (Turney et al. 2012, Wildeman et al. 2013). This important line of research is still emerging, and future research focused on clarifying the scope of incarceration's impact on mental health outcomes and the specific mechanisms that produce such effects would advance this research area. Similarly, we were able to only broadly consider how incarceration may disrupt family functioning in ways that are related to a host of developmental and health outcomes for both children and spouses of inmates (see Turney 2015, Turney \& Wildeman 2015). Further inquiry into this area is important to determine the breadth and range of the collateral consequences of incarceration and to test the possible causal pathways linking incarceration and health.

\section{CONCLUSION}

In the last decade there has been a sustained research focus on the health consequences of incarceration. Sociologists across a range of subfields, including criminology, stratification, life course processes, family functioning, and medical sociology, have undertaken research on the topic. In this review we attempt to summarize this rapidly expanding literature while pointing to areas in which additional research is warranted. Despite the wealth of articles published in recent years, research in the area is still at its nascent stages, as is-from a historical context—our understanding of the penal system and its effects on society. As the number of individuals released from prison grows, and as they advance in age, research on the relationship between incarceration and health will continue to speak to a host of critical academic, social, and policy issues. To that end, we view the important work to date as a starting point for future research in the area.

\section{Acknowledgments}

The authors thank Taylor Damrow for valuable research assistance.

\section{LITERATURE CITED}

Apel R, Blokland AAJ, Nieuwbeerta P, van Schellen M. The impact of imprisonment on marriage and divorce: a risk set matching approach. J Quant Criminol. 2010; 26(2):269-300.

Arditti JA, Lambert-Shute J, Joest K. Saturday morning at the jail: implications of incarceration for families and children. Fam Relat. 2003; 52(3):195-204.

2003). Of course, mental health problems resulting from incarceration likely follow the former inmate following release from prison. Schnittker et al. (2012) found long-lasting effects of incarceration on a range of psychiatric disorders, including major depressive disorder, bipolar disorder, and dysthymia, and Schnittker \& John (2007) argue that many of the other negative outcomes resulting from incarceration stem largely from the stigma of imprisonment. The mental health outcomes of incarceration extend not only beyond the prison but also beyond the inmate. Mental health and/or behavioral problems are greater among children with parents who have been incarcerated (Murray et al. 2012, Wakefield \& Wildeman 2011), and those children are more likely to experience the negative effects of some mental health treatment outcomes (Phillips et al. 2002). In one large US survey, two-thirds of state prison inmates and over $80 \%$ of jail inmates with mental health problems had not received treatment for those problems since admission ( James \& Glaze 2006). In contrast, a number of recent studies suggest mental health treatment for probationers and parolees can improve both clinical and criminal outcomes (Skeem \& Eno Louden 2006). Methodologically, the causal direction of the relationship between incarceration and mental health is not always clear. Similarly, the limitation of selection effects is at least as challenging if not more so for the incarceration-mental health association as it is for the incarceration-physical health association. In sum, instead of attempting to introduce and address these topics and a long list of others that are crucial when considering the association between incarceration and mental health, we direct readers to the work we cite here as a starting point for the large and important literature on this topic. 
Backlund E, Sorlie PD, Johnson NJ. The shape of the relationship between income and mortality in the United States: evidence from the National Longitudinal Mortality Study. Ann Epidemiol. 1996; 6(1):1-9. [PubMed: 8680618]

Bick JA. Infection control in jails and prisons. Clin Infect Dis. 2007; 45(8):1047-55. [PubMed: 17879924]

Binswanger IA, Blatchford PJ, Lindsay RG, Stern MF. Risk factors for all-cause, overdose, and early deaths after release from prison in Washington state. Drug Alcohol Depend. 2011; 117(1):1-6. [PubMed: 21295414]

Binswanger IA, Krueger PM, Steiner JF. Prevalence of chronic medical conditions among jail and prison inmates in the United States compared with the general population. J Epidemiol Community Health. 2009; 63(11):912-19. [PubMed: 19648129]

Binswanger IA, Stern MF, Deyo RA, Heagerty PJ, Cheadle A, et al. Release from prison: a high risk of death for former inmates. N Engl J Med. 2007; 356(2):157-65. [PubMed: 17215533]

Bird SM, Hutchinson SJ. Male drugs-related deaths in the fortnight after release from prison: Scotland, 1996-99. Addiction. 2003; 98(2):185-90. [PubMed: 12534423]

Braman D. Doing Time on the Outside: Incarceration and Family Life in Urban America. Ann Arbor: Univ. Michigan Press; 2004.

Cho RM. Impact of maternal imprisonment on children's probability of grade retention. J Urban Econ. 2009a; 65(1):11-23.

Cho RM. The impact of maternal imprisonment on children's educational achievement: results from children in Chicago public schools. J Hum Resour. 2009b; 44(3):772-97.

Comfort M. Punishment beyond the legal offender. Annu Rev Law Soc Sci. 2007; 3:271-96.

Comfort M. Doing Time Together: Love and Family in the Shadow of the Prison. Chicago: Univ. Chicago Press; 2008.

Dirkzwager A, Nieuwbeerta P, Blokland AAJ. Effects of first-time imprisonment on postprison mortality: a 25-year follow-up study with a matched control group. J Res Crime Delinq. 2012; 49(3):383-419.

Ditton PM. Mental Health and Treatment of Inmates and Probationers. Washington, DC: Bureau of Justice Statistics; 1999. http://www.bjs.gov/content/pub/pdf/mhtip.pdf

Ecob R, Davey Smith G. Income and health: What is the nature of the relationship? Soc Sci Med. 1999; 48(5):693-705. [PubMed: 10080369]

Farrell M, Marsden J. Acute risk of drug-related death among newly released prisoners in England and Wales. Addiction. 2008; 103(2):251-55. [PubMed: 18199304]

Fazel SF, Danesh J. Serious mental disorder in 23,000 prisoners: a systematic review. Lancet. 2002; 359(9306):545-50. [PubMed: 11867106]

Geller A, Garfinkel I, Western B. Paternal incarceration and support for children in fragile families. Demography. 2011; 48(1):25-47. [PubMed: 21318455]

Glaser R, Kiecolt-Glaser JK. Stress-induced immune dysfunction: implications for health. Nat Rev Immunol. 2005; 5(3):243-51. [PubMed: 15738954]

Glaze LE, Parks E. Correctional Populations in the United States, 2011. Washington, DC: Bureau of Justice Statistics; 2012. http://www.bjs.gov/content/pub/pdf/cpus11.pdf

Goffman A. On the run: wanted men in a Philadelphia ghetto. Am Sociol Rev. 2009; 74(3):339-57.

Graham A. Post-prison mortality: unnatural death among people released from Victorian prisons between January 1990 and December 1999. Aust N Z J Criminol. 2003; 36(1):94-108.

Greenberg GA, Rosenheck RA. Jail incarceration, homelessness, and mental health: a national study. Psychiatr Serv. 2008; 59(2):170-77. [PubMed: 18245159]

Haney C. Mental health issues in long-term solitary and "supermax" confinement. Crime Delinq. 2003; 49(1):124-56.

Harris A, Evans H, Beckett K. Drawing blood from stones: legal debt and social inequality in the contemporary United States. Am J Sociol. 2010; 115(6):1753-99.

Harzke AJ, Baillargeon JG, Kelley MF, Pruitt SL, Pulvino JS, Paar DP. Leading medical causes of mortality among male prisoners in Texas, 1992-2003. J Correct Health Care. 2011; 17(3):241-53. [PubMed: 21576121] 
Houle B. The effect of incarceration on adult male BMI trajectories, USA, 1981-2006. J Racial Ethn Health Disparities. 2014; 1(1):21-28. [PubMed: 24812594]

Huebner BM. The effect of incarceration on marriage and work over the life course. Justice Q. 2005; 22(3):281-303.

James DJ, Glaze LE. Mental Health Problems of Prison and Jail Inmates. Washington, DC: Bureau of Justice Statistics; 2006. http://www.bjs.gov/content/pub/pdf/mhppji.pdf

Johnson EI, Easterling B. Understanding unique effects of parental incarceration on children: challenges, progress, and recommendations. J Marriage Fam. 2012; 74(2):342-56.

Johnson RC, Raphael S. The effects of male incarceration dynamics on acquired immune deficiency syndrome infection rates among African American women and men. J Law Econ. 2009; 52(2): 251-93.

Kariminia A, Butler TG, Corben SP, Levy MH, Grant L, et al. Extreme cause-specific mortality in a cohort of adult prisoners-1988 to 2002: a data-linkage study. Int J Epidemiol. 2007a; 36(2):31016. [PubMed: 17158524]

Kariminia A, Law MG, Butler TG, Corben SP, Levy MH, et al. Factors associated with mortality in a cohort of Australian prisoners. Eur J Epidemiol. 2007b; 22(7):417-28. [PubMed: 17668280]

Kjelsberg E, Laake P. Is the high mortality risk in sentenced offenders independent of previous imprisonment? Eur J Epidemiol. 2010; 25(4):237-43. [PubMed: 20213341]

Knapp LG, Kelly-Reid JE, Ginder SA. Postsecondary Institutions in the United States: Fall 2007, Degrees and Other Awards Conferred: 2006-07, and 12-Month Enrollment: 2006-07 (NCES 2008-159). Washington, DC: NCES, Inst. Educ. Sci., US Dep. Educ; 2008. http://nces.ed.gov/ pubs2008/2008159rev.pdf

Krinsky CS, Lathrop SL, Brown P, Nolte KB. Drugs, detention, and death: a study of the mortality of recently released prisoners. Am J Forensic Med Pathol. 2009; 30(1):6-9. [PubMed: 19237844]

Lee H, Wildeman C, Wang EA, Matusko N, Jackson JS. A heavy burden: the cardiovascular health consequences of having a family member incarcerated. Am J Public Health. 2014; 104(3):421-27. [PubMed: 24432879]

Lim S, Levanon Seligson A, Parvez FM, Luther CW, Mavinkurve MP, et al. Risks of drug-related death, suicide, and homicide during the immediate post-release period among people released from New York City jails, 2001-2005. Am J Epidemiol. 2012; 175(6):519-26. [PubMed: 22331462]

Lindquist $\mathrm{CH}$, Lindquist CA. Gender differences in distress: mental health consequences of environmental stress among jail inmates. Behav Sci Law. 1997; 15(4):503-23. [PubMed: 9433751]

Lopoo LM, Western B. Incarceration and the formation and stability of marital unions. J Marriage Fam. 2005; 67(3):721-34.

Maruschak LM. Medical Problems of Prisoners. Washington, DC: Bureau of Justice Statistics; 2008. http://bjs.gov/content/pub/pdf/mpp.pdf

Maruschak LM. HIV in Prisons, 2001-2010. Washington, DC: Bureau of Justice Statistics; 2012. http://www.bjs.gov/content/pub/pdf/hivp10.pdf

Massoglia M. Incarceration as exposure: the prison, infectious disease, and other stress-related illnesses. J Health Soc Behav. 2008a; 49(1):56-71. [PubMed: 18418985]

Massoglia M. Incarceration, health, and racial disparities in health. Law Soc Rev. 2008b; 42(2):275306.

Massoglia M, Pare PP, Schnittker J, Gagnon A. The relationship between incarceration and premature ' mortality: gender specific evidence. Soc Sci Res. 2014; 46(1):142-54. [PubMed: 24767596]

Massoglia M, Remster B, King RD. Stigma or separation? Understanding the incarceration-divorce relationship. Soc Forces. 2011; 90(1):133-55.

Massoglia M, Schnittker J. No real release: the health effects of incarceration. Contexts. 2009; 8(1): $38-42$.

Massoglia M, Warner C. The consequences of incarceration: challenges for scientifically informed and policy relevant research. Criminol Public Policy. 2011; 10(3):851-63.

McEwen BS, Stellar E. Stress and the individual. Mechanisms leading to disease. Arch Intern Med. 1993; 153(18):2093-101. [PubMed: 8379800] 
Møller LF, Matic S, Van Den Bergh BJ, Moloney K, Hayton P, Gatherer A. Acute drug-related mortality of people recently released from prisons. Public Health. 2010; 124(11):637-39. [PubMed: 20888607]

Mumola CJ. Medical Causes of Death in State Prisons, 2001-2004. Washington, DC: Bureau of Justice Statistics; 2007. http://www.bjs.gov/content/pub/pdf/mcdsp04.pdf

Murray J, Farrington DP. The effects of parental imprisonment on children. Crime Justice. 2008; 37(1): 133-206.

Murray J, Farrington DP, Sekol I. Children's antisocial behavior, mental health, drug use, and educational performance: a systematic review and meta-analysis. Psychol Bull. 2012a; 138(2): 175-210. [PubMed: 22229730]

Murray J, Loeber R, Pardini D. Parental involvement in the criminal justice system and the development of youth theft, marijuana use, depression, and poor academic performance. Criminology. 2012b; 50(1):255-302.

Nurse J, Woodcock P, Ormsby J. Influence of environmental factors on mental health within prisons: focus group study. Br Med J. 2003; 327(7413):480-83. [PubMed: 12946970]

Pager D. The mark of a criminal record. Am J Sociol. 2003; 108(5):937-75.

Pager D, Western B, Sugie N. Sequencing disadvantage: barriers to employment facing young black and white men with criminal records. Ann Am Acad Polit Soc Sci. 2009; 623(1):195-213.

Patterson EJ. Incarcerating death: mortality in U.S. state correctional facilities, 1985-1998. Demography. 2010; 47(3):587-607. [PubMed: 20879679]

Patterson EJ. The dose-response of time served in prison on mortality: New York State, 1989-2003. Am J Public Health. 2013; 103(3):523-28. [PubMed: 23327272]

Pearlin LI. The sociological study of stress. J Health Soc Behav. 1989; 30(3):241-56. [PubMed: 2674272]

Pettit B, Western B. Mass imprisonment and the life course: race and class inequality in US incarceration. Am Sociol Rev. 2004; 69(2):151-69.

Phillips SD, Burns BJ, Wagner HR, Kramer TL, Robbins JM. Parental incarceration among adolescents receiving mental health services. J Child Fam Stud. 2002; 11(4):385-99.

Pratt D, Piper M, Appleby L, Webb R, Shaw J. Suicide in recently released prisoners: a populationbased cohort study. Lancet. 2006; 368(9530):119-23. [PubMed: 16829295]

Pridemore WA. The mortality penalty of incarceration: evidence from a population-based case-control study. J Health Soc Behav. 2014; 55(2):215-33. [PubMed: 24793163]

Pridemore WA, Tomkins S, Eckhardt K, Kiryanov N, Saburova L. A case-control analysis and educational and marital status differentials in alcohol- and non-alcohol-related mortality among working-age Russian males. Eur J Public Health. 2010; 20(5):569-75. [PubMed: 20219866]

Ramakers A, Apel R, Nieuwbeerta P, Dirkzwager A, van Wilsem J. Imprisonment length and postimprisonment employment prospects. Criminology. 2014; 52(3):399-427.

Roettger ME, Boardman JD. Parental incarceration and gender-based risks for increased body mass index: evidence from the National Longitudinal Study of Adolescent Health in the United States. Am J Epidemiol. 2012; 175(7):636-44. [PubMed: 22437187]

Roettger ME, Swisher R. Racial and ethnic differences in associations between father's incarceration and son's delinquency and arrest. Criminology. 2011; 49(4):1109-47.

Roettger ME, Swisher KD, Chavez J. Paternal incarceration and trajectories of marijuana and other illegal drug use from adolescence into young adulthood: evidence from longitudinal panels of males and females in the United States. Addiction. 2011; 106(1):121-32. [PubMed: 20874861]

Rosen DL, Schoenbach VJ, Wohl DA. All-cause and cause-specific mortality among men released from state prison, 1980-2005. Am J Public Health. 2008; 98(12):2278-84. [PubMed: 18923131]

Rosen DL, Wohl DA, Schoenbach VJ. All-cause and cause-specific mortality among black and white North Carolina state prisoners, 1995-2005. Ann Epidemiol. 2011; 21(10):719-26. [PubMed: 21737304]

Ross CE, Mirowsky J. Does employment affect health? J Health Soc Behav. 1995; 36(3):230-43. [PubMed: 7594356] 
Sampson RJ, Laub JH. Crime in the Making: Pathways and Turning Points Through Life. Cambridge, MA: Harvard Univ. Press; 1993.

Schnittker J, John A. Enduring stigma: the long-term effects of incarceration on health. J Health Soc Behav. 2007; 48(2):115-30. [PubMed: 17583269]

Schnittker J, Massoglia M, Uggen C. Out and down: the effects of incarceration on psychiatric disorders and disability. J Health Soc Behav. 2012; 53:448-64. [PubMed: 23197484]

Schwartz-Soicher O, Geller A, Garfinkel I. The effect of paternal incarceration on material hardship. Soc Serv Rev. 2011; 85(3):447-73. [PubMed: 24839314]

Seaman SR, Brettle RP, Gore SM. Mortality from overdose among injecting drug users recently released from prison: database linkage study. Br Med J. 1998; 316(7129):426-28. [PubMed: 9492665]

Siennick SE, Stewart EA, Staff J. Explaining the association between incarceration and divorce. Criminology. 2014; 52(3):371-98. [PubMed: 25598544]

Skeem J, Eno Louden J. Toward evidence-based practice for probationers and parolees mandated to mental health treatment. Psychiatr Serv. 2006; 57(3):333-42. [PubMed: 16524990]

Snyder TD, Dillow SA. Digest of Education Statistics 2009 (NCES 2010-013). Washington, DC: NCES, US Dep. Educ; 2010. http://nces.ed.gov/pubs2010/2010013_0.pdf

Spaulding AC, Seals RM, McCallum VA, Perez SD, Brzozowski AK, Steenland NK. Prisoner survival inside and outside of the institution: implications for health-care planning. Am J Epidemiol. 2011; 173(5):479-87. [PubMed: 21239522]

Thoits PA. Stress, coping, and social support processes: Where are we? What next? J Health Soc Behav. 1995; 35:S53-S79.

Turney K. Stress proliferation across generations? Examining the relationship between parental incarceration and childhood health. J Health Soc Behav. 2014; 55(3):302-19. [PubMed: 25138199]

Turney K. Hopelessly devoted? Relationship quality during and after incarceration. J Marriage Fam. 2015; 77(2):480-95.

Turney K, Wildeman C. Detrimental for some? The heterogeneous effects of maternal incarceration on child wellbeing. Criminol Public Policy. 2015; 14(1):125-56.

Turney K, Wildeman C, Schnittker J. As fathers and felons: explaining the effects of current and recent incarceration on major depression. J Health Soc Behav. 2012; 53:467-83.

Uggen C, Manza J, Thompson M. Citizenship, democracy, and the civic reintegration of criminal offenders. Ann Am Acad Polit Soc Sci. 2006; 605(1):281-310.

Varan AK, Mercer DW, Stein MS, Spaulding AC. Hepatitis C seroprevalence among prison inmates since 2001: still high but declining. Public Health Rep. 2014; 129(2):187-95. [PubMed: 24587554]

Verbrugge LM. Marital status and health. J Marriage Fam. 1979; 41(2):267-85.

Verger P, Rotily M, Prudhomme J, Bird S. High mortality rates among inmates during the year following their discharge from a French prison. J Forensic Sci. 2003; 48(3):614-16. [PubMed: 12762532]

Wakefield S, Uggen C. Incarceration and stratification. Annu Rev Sociol. 2010; 36:387-406.

Wakefield S, Wildeman C. Mass imprisonment and racial disparities in childhood behavioral problems. Criminol Public Policy. 2011; 10(3):793-817.

Wakefield S, Wildeman C. Children of the Prison Boom: Mass Incarceration and the Future of American Inequality. New York: Oxford Univ. Press; 2013.

Waller MR, Swisher R. Fathers' risk factors in fragile families: implications for "healthy" relationships and father involvement. Soc Probl. 2006; 53(3):392-420.

Wang EA, Pletcher M, Lin F, Vittinghoff E, Kertesz SG, et al. Incarceration, incident hypertension, and access to health care: findings from the Coronary Artery Risk Development in Young Adults (CARDIA) study. Arch Intern Med. 2009; 169(7):687-93. [PubMed: 19364998]

Western B. The impact of incarceration on wage mobility and inequality. Am Sociol Rev. 2002; 67(4): $526-46$. 
Western B, Kling JR, Weiman DF. The labor market consequences of incarceration. Crime Delinq. 2001; 47(3):410-27.

Western B, Wildeman C. The black family and mass incarceration. Ann Am Acad Polit Soc Sci. 2009; 621(1):221-42.

Wheaton B. Sampling the stress universe. In: Avison WR, Gotlib IH, editorsStress and Mental Health: Contemporary Issues and Prospects for the Future. New York: Plenum; 1994. 77-114.

Wildeman C. Parental imprisonment, the prison boom, and the concentration of childhood disadvantage. Demography. 2009; 46(2):265-80. [PubMed: 21305393]

Wildeman C. Paternal incarceration and children's physically aggressive behaviors: evidence from the Fragile Families and Child Wellbeing Study. Soc Forces. 2010; 89(1):285-309.

Wildeman C. Imprisonment and infant mortality. Soc Probl. 2012; 59(2):228-57.

Wildeman C, Muller C. Mass imprisonment and inequality in health and family life. Annu Rev Law Soc Sci. 2012; 8:11-30.

Wildeman C, Schnittker J, Turney K. Despair by association? The mental health of mothers with children by recently incarcerated fathers. Am Sociol Rev. 2012; 77(2):216-43.

Wildeman C, Turney K. Positive, negative, or null? The effects of maternal incarceration on children's behavioral problems. Demography. 2014; 51(3):1041-68. [PubMed: 24719275]

Wildeman C, Wakefield S, Turney K. Misidentifying the effects of parental incarceration? A comment on Johnson and Easterling 2012. J Marriage Fam. 2013; 75(1):252-58.

Wildeman C, Western B. Incarceration in fragile families. Future Children. 2010; 20(2):157-77.

Wilson WJ. The Truly Disadvantaged: The Inner City, the Underclass, and Public Policy. Chicago: Univ. Chicago Press; 1987. 